\title{
Entre mediações e (re) configurações: a trajetória do Fórum de Agricultura Familiar
}

Carla Michele Rech*

\section{Resumo}

0 objetivo desse artigo é apresentar resultados da investigação sobre uma experiência de participação social e gestão de políticas públicas voltadas ao meio rural no extremo sul do Brasil. Trata-se de um estudo de caso realizado junto ao Fórum de Agricultura Familiar da região sul do Rio Grande do Sul, criado em 1995, e que, a partir de 2004, adquiriu uma interface socioestatal. Partimos do pressuposto de que os processos de gestão local e participação cidadã envolvem uma complexidade de fenômenos que, de forma relacional, configuram as relações entre os agentes, muitos deles promovidos por processos de mediação social. Essas relações geram interdependências multidimensionais que se complexificam com a aproximação do Estado e implantação de políticas públicas. Os resultados demonstram que a capacidade de adaptação do Fórum aos diferentes contextos político-institucionais e ação de mediadores tem permitido sua manutenção e efetividade do processo de participação social.

\section{Palavras-chave}

Participação. Mediação social. Agricultura familiar.

\section{Abstract}

This paper sought to present the results of a research about a social participation and management of public policies experience at rural areas in southern Brazil. This case study was supported by the Family Farming Forum at the Southern Region of Rio Grande do Sul state. The Forum was created in 1995 and since 2004 it has acquired an interface involving state and societal actors. We assumed that local management processes and social participation involve a series of phenomena configuring relationships between agents - many of them advanced by processes of social mediation. These relationships generate multidimensional interdependencies which grow in complexity when drawn closer to the government and to the implementation of public policies. The results showed that the adaptability of the Forum to

\footnotetext{
* Doutoranda do Programa de Pós-graduação em Sociologia da Universidade Federal do Rio Grande do Sul (UFRGS); e mestra em Sociologia pelo Programa de Pós-Graduação em Sociologia (PPGS) da Universidade Federal de Pelotas (UFPel). E-mail: carlatsul@yahoo.com.br.
} 
different political and institutional contexts as well as the action of mediators have allowed its maintenance and its effectiveness in the social participation process.

\section{Keywords}

Participation. Social mediation. Family farming.

\section{Introdução}

Diversos estudos têm demonstrado a efervescência de processos participativos desencadeados a partir da redemocratização brasileira, na década de 1990 . No Brasil, é consenso na literatura que a promulgação da Constituição Federal de 1988 redesenhou institucionalmente o Estado, ao introduzir novos instrumentos de gestão social das políticas públicas. Arretche (2003) destaca que já não é nenhuma novidade afirmar que, nas últimas décadas, a gestão local de políticas públicas tem sido portadora de expectativas as mais positivas com relação a resultados desejáveis da ação do Estado. Democratização do processo decisório; eficiência na gestão das políticas públicas; controle social; qualidade da informação entre decisores, provedores e beneficiários estão no topo da lista dos resultados virtuosos da descentralização, em oposição aos vícios e problemas gerados pelas estruturas centralizadas instituídas ao longo do século 20.

É importante considerar, no debate sobre este tema, a perspectiva de Isunza Vera (2007) acerca do conceito de participação social, que, em sua perspectiva, também está diretamente atrelada à esfera estatal,

O que denominamos "participação cidadã", "participação social” ou simplesmente "participação", é a relação entre cidadãos e o Estado que toma múltiplas formas, com diversas intensidades e intencionalidades (...) em qualquer caso, os cidadãos mobilizam energias e recursos em um fluxo contínuo de intercâmbios com as instituições do Estado. O Estado e a sociedade tomam muitas facetas concretas em seus encontros, configurando as interfaces na que ambos, sociedade e Estado, se materializam em atores concretos (ISUNZA VERA, 2007, p.302 - tradução da autora).

Fenômenos ligados à organização e participação social têm sido observados também no meio rural, inicialmente em torno da constituição de uma nova 
categoria social denominada agricultura familiar ${ }^{1}$. Produto de lutas sociais, a emergência do que antes se denominava "pequenos agricultores" no cenário nacional culminou, entre outras ações, na formulação do Programa Nacional de Fortalecimento da Agricultura Familiar - Pronaf ${ }^{2}$, em decorrência do reconhecimento dessa categoria pelo Estado brasileiro.

No meio acadêmico, a agricultura familiar passou gradativamente a ocupar espaço nas pesquisas, tornando-se tema relevante na área dos estudos sociais, a partir dos anos 1990. Nesse contexto, pesquisas relacionadas às dinâmicas institucionais e à participação dos agentes ligados ao mundo rural têm demonstrado que, especialmente em contextos de implementação de políticas públicas, determinados repertórios de ação coletiva são estimulados pelo Estado, oportunizando práticas participativas de segmentos até então excluídos.

Em meio a esse movimento nacional, destaca-se a organização social dos agricultores familiares do Rio Grande do Sul. Na região sul do estado, em meados da década de 90 do século XX, um pequeno grupo de pessoas ligadas às organizações que apoiavam pequenos agricultores da região, em conjunto com a chefia geral e pesquisadores da Embrapa Clima Temperado ${ }^{3}$,

\footnotetext{
${ }^{1}$ De acordo com a Resolução n. 48/2004/MDA/CONDRAF, entende-se por agricultor(a) familiar o conceito adotado pelo Pronaf, que inclui: a) produtores(as) rurais cujo trabalho seja de base familiar, quer sejam proprietários(as), posseiros(as), arrendatários(as), parceiros(as) ou concessionários(as) da Reforma Agrária; b) remanescentes de quilombos e indígenas; c) pescadores(as) artesanais que se dediquem à pesca artesanal, com fins comerciais, explorem a atividade como autônomos, com meios de produção próprios ou em parceria com outros pescadores artesanais; d) extrativistas que se dediquem à exploração extrativista ecologicamente sustentável; e) silvicultores(as) que cultivam florestas nativas ou exóticas, com manejo sustentável; e f) aquicultores(as) que se dediquem ao cultivo de organismos cujo meio normal ou mais frequente de vida seja a água.

${ }^{2}$ Conforme destacam Schneider; Cazella e Mattei (2009, p. 23 - 24) o programa nasceu com a finalidade de prover crédito agrícola e apoio institucional aos pequenos produtores rurais. Foi produto de uma reformulação em 1995, pelo governo Fernando Henrique Cardoso, do Programa de Valorização da Pequena Produção Rural (Provap) criado em 1994 durante o governo Itamar Franco. Essas modificações deram origem ao Pronaf, em 1996, cuja institucionalização ocorreu através do Decreto Presidencial n. 1.946 datado de 28 de julho de 1996.

3 “A Embrapa Clima Temperado é uma unidade descentralizada da Empresa Brasileira de Pesquisa Agropecuária, Embrapa, vinculada ao Ministério da Agricultura e Pecuária (MAPA), localizada em Pelotas/RS, formada a partir da fusão de dois centros de pesquisa existentes na região sul do Rio Grande do Sul: o Centro de Pesquisas de Terras Baixas - CPATB e o Centro de Pesquisas de Fruteiras de Clima Temperado - CPFT. Uma das bases físicas que compõe essa Unidade é a Estação Experimental da Cascata" (PERERA; GOMES, 2009, p.137).
} 
decidiram criar um espaço de debate e de elaboração de propostas para incidir na agenda de pesquisas da Embrapa, na perspectiva de inserir o tema da agricultura familiar.

O local dos encontros foi a Estação Experimental Cascata (EEC) da Embrapa Clima Temperado, localizada em Pelotas/ Rio Grande do Sul. Nascia assim, em 1995, o Fórum Regional da Agricultura Familiar, que se reúne, desde então, ininterruptamente, por meio de encontros mensais, dos quais participam organizações governamentais e não governamentais ligadas aos agricultores familiares, assentados de reforma agrária, pescadores artesanais e comunidades quilombolas ${ }^{4}$.

Nessa trajetória de quase duas décadas de funcionamento, cabe destacar um fato relevante que alterou sobremaneira as configurações desse espaço. Em 2004, o Fórum adquiriu uma interface socioestatal, passando a atuar como colegiado territorial do território Zona Sul do Estado. Esse processo decorreu da implantação do Programa Nacional de Desenvolvimento Sustentável dos Territórios Rurais, uma proposta de descentralização do governo federal brasileiro (2003-2011), coordenado pela Secretaria de Desenvolvimento Territorial do Ministério do Desenvolvimento Agrário (SDT/MDA).

O presente artigo tem por objetivo apresentar os resultados da pesquisa de mestrado acadêmico, na qual se analisou uma série de nove anos de atividades desse fórum (2004-2012), procurando identificar quais elementos permitiram a manutenção desse espaço de participação social no extremo sul do Brasil, enfatizando a relevância dos resultados obtidos com o processo e para o processo, numa relação de retroalimentação.

Utilizamos como referência teórica os pressupostos da epistemologia crítica (DE LA GARZA, 2001); da sociologia da interdependência (ELIAS, 2008); e pesquisas realizadas em processos participativos de implementação de políticas públicas no mundo rural brasileiro (SILVA, 2007; FAVARETO; DEMARCO, 2009; MATTEI; CAZELLA; SCHNEIDER, 2009; SCHMITT, 2012). Também foram utilizados aportes teóricos da sociologia norteamericana relativos à interdependência entre o contexto político-

\footnotetext{
${ }^{4}$ Segundo o Art. 2º , da Portaria 98/2007 da Fundação Cultural Palmares, "consideram-se remanescentes das comunidades dos quilombos os grupos étnicos raciais, segundo critérios de auto-atribuição, com trajetória histórica própria, dotados de relações territoriais específicas, com presunção de ancestralidade negra relacionada com formas de resistência à opressão histórica sofrida" (BRASIL, 2007).
} 
institucional e os repertórios de ação coletiva (McADAM; TARROW; TILLY, 2001; SKOCPOL, 2003) e das relações de mediação social (NEVES, 2008; NUSSBAUMER; ROS, 2011).

Essa fundamentação nos convida a considerar o passado e o presente nas interpretações sobre processos de participação social, os quais se encontram em constante transformação, formando configurações mutáveis e transitórias. Além disso, chama atenção para o fato de que os processos de participação e de mediação social, longe de ocorrerem de forma espontânea e imediata, se dão em um contexto determinado, em dado período e sob certas circunstâncias, e, por tal motivo, sofrem a influência do contexto político-institucional.

Neves (2008: 29) observa, neste sentido, que a ação de mediadores também tem provocado mudanças no aparato estatal, forjando um papel central à negociação e à formação de acordos. Segundo Jean Roca (2001 apud Moruzzi MARQUES, 2009, p.100), no cenário de relação com o Estado encontram-se as organizações não governamentais (ONGs), cuja legitimidade advém de três fontes: "o exercício garantido de um know-how técnico; a afirmação de valores que tenham sentido na esfera social de um mundo 'desencantado' e a elaboração de novas formas de representação dos sem-voz”. Para Moruzzi Marques (2009, p.100), "as ONGs podem certamente completar a ação do Estado e apoiar, de forma eficaz, as organizações populares”.

Além disso, dados de pesquisas realizadas em contextos de implementação de políticas públicas no mundo rural destacam a necessidade de se levar em consideração também os "constrangimentos" impostos aos espaços participativos, especialmente os relacionados à esfera estatal, os quais geralmente possuem "limites legais-regimentais", bem como os custos de participação, e aos diferenciais de recursos (SILVA; MARQUES, 2009, p.17), aspectos relevantes no tocante à participação social de agentes ligados à sociedade civil.

Essa dimensão de análise relativa à mobilização de recursos é destacada também por Schmitt (2012, p.11), ao afirmar que "processos organizativos implicam custos e que, para sua continuidade ao longo do tempo, as organizações necessitam criar mecanismos de captação e utilização eficaz de recursos (financeiros, materiais, humanos, conhecimento, etc.)”.

Skocpol (2003) dá ênfase à investigação em elementos relevantes para análise: o padrão de financiamento da vida associativa, tendo em vista que a dimensão de mobilização de recursos é estratégica, já que há um custo nesses processos; a influência do contexto político-institucional para a conformação 
dos processos organizativos e com o apoio da mídia, a presença de recursos humanos e a capacidade de mobilização têm influenciado as organizações associativas.

Segundo a autora, não existe uma causa única nem uma institucionalidade única; o que existe são vários mecanismos que se articulam para gerar resultados, especialmente as condições políticas e sociais. Por isso, há uma ênfase na investigação dos processos internos e sua dinâmica relacional, especialmente as ofertas de participação social e política em determinados contextos (SKOCPOL, 2003, p.176).

Como fonte de obtenção e interpretação dos dados, foi utilizada predominantemente a observação participante (ANGROSINO, 2009; GIL, 2009; BECKER, 1999), observação retrospectiva ${ }^{5}$ (MARTINS, 2008) e a análise documental (CELLARD, 2010). Os dados obtidos por meio da observação foram acompanhados da análise documental e cotejados com a realização de entrevistas (GIL, 2009) qualitativas (focadas e por pauta) com membros do Fórum, especialmente em cargos de direção desse espaço, e representantes das comunidades quilombolas e dos pescadores artesanais que, sociologicamente, dão sentido ao processo investigado, pois se trata de atores que estavam, no início, "fora de cena".

\section{A trajetória do Fórum: entre mediações e (re) configurações}

Buscando identificar e compreender quais foram as principais condições de possibilidade que oportunizaram a manutenção desse espaço por quase duas décadas, apresentamos, a seguir, uma breve caracterização das diferentes configurações do Fórum em cada um dos anos investigados e as modificações ocorridas especificamente no período de 2004 a 2012, sem desconsiderar o momento de sua constituição até o momento de início das análises.

As duas hipóteses centrais que guiaram a investigação foram que a manutenção do Fórum se deveu, em parte, à influência do contexto político-

\footnotetext{
${ }^{5}$ Perspectiva metodológica inaugurada pelo sociólogo Jose de Souza Martins. Nela, utilizam-se como banco de dados as próprias lembranças. Os fatos experienciados são reconsiderados "a posteriori" como dados, ao interior de uma espécie de observação participante. A escolha dessa abordagem metodológica justifica-se pelo fato de que a presente investigadora acompanhou as atividades do Fórum de 2003 a 2010, inicialmente como secretária executiva e posteriormente como assessora técnica da política de desenvolvimento territorial.
} 
institucional e à ação de mediadores sociais, especialmente do Centro de Apoio ao Pequeno Agricultor (CAPA) ${ }^{6}$, no referente ao ingresso de novos grupos.

A primeira configuração do Fórum pode ser caracterizada pelo período de sua fundação ao processo de rearticulação (1995 até início de 2004), sendo seu surgimento diretamente ligado à mudança da chefia geral da Embrapa Clima Temperado. Segundo dados encontrados, o novo gestor buscava revitalizar o centro de pesquisas da Embrapa, com ênfase na agricultura familiar, o que contribuiu para a configuração do Fórum, processo influenciado por um conjunto de transformações no contexto regional, por exemplo, a implantação dos assentamentos ${ }^{7}$ de reforma agrária.

Chama atenção, na análise dos documentos e na observação realizada, que desde o início os idealizadores do Fórum estabeleceram um conjunto de regras e de recursos para a materialização dessa prática - o objetivo, a dinâmica e a coordenação dos encontros, com destaque para a frequência das reuniões, realizadas todos os meses, sempre na mesma época ${ }^{8}$.

No registro sobre o histórico da constituição do Fórum, também fica evidente o envolvimento da Embrapa no apoio ao funcionamento desse espaço, sendo, principalmente, o ponto de encontro das organizações dentro de uma estrutura pública. Quanto às organizações participantes ${ }^{9}$ à época,

\footnotetext{
6 "O Centro de Apoio ao Pequeno Agricultor (CAPA) é uma organização não-governamental ligada à IECLB (Igreja Evangélica de Confissão Luterana no Brasil), criada em 1978, que busca contribuir de forma decisiva para a prática social e de serviço junto a agricultores familiares e outros públicos ligados à área rural. A luta é pela afirmação da agricultura familiar como parte de uma estratégia de desenvolvimento rural sustentável" (CAPA, 2008)

${ }^{7}$ Segundo dados levantados, (CAPA, 2009, p.14) "O território possui um dos maiores núcleos de assentamentos do estado, sendo 117 ao todo com 3.969 famílias, o que corresponde a $40 \%$ do total do RS, concentrando-se nos municípios de Candiota e Hulha Negra".

${ }^{8}$ Ordinariamente, as reuniões do Fórum têm ocorrido sem interrupção desde a sua fundação, na forma de um encontro mensal, de março a dezembro, sempre na $2^{2}$ terça-feira de cada mês.

${ }^{9}$ Constavam na lista de convidados 22 organizações, a saber: UFPel, Agência da Lagoa Mirim (ALM/UFPel), Secretaria Estadual do Meio Ambiente (SEMA), Banco do Brasil, Banrisul Pelotas, Sicredi, Corede Sul, Comgides/Pelotas, Coopar, Coopal, Capa, Unaic, Fepagro/Rio Grande, IRGA, Fepam, Fórum da Lagoa dos Patos, Fapeg, UCPel, MPA, Secretarias Municipais de Agricultura de Santana da Boa Vista, Arroio do Padre, Piratini, São Lourenço do Sul, Cristal, Pelotas, Morro Redondo, Arroio Grande, Emater e um conjunto de escritórios municipais do Sindicato dos Trabalhadores Rurais (STR) da região sul (Documento do Fórum de Agricultura Familiar, abril de 2004).
} 
segundo relato de entrevista realizada, no início do Fórum a participação de representantes do sindicato de trabalhadores rurais era expressiva.

Um aspecto da dinâmica do Fórum feita durante a observação participante chama atenção e merece ser destacado: para além da formalização dos convites para as reuniões, existe uma realidade sociológica que determina a participação efetiva das organizações. Apesar de a secretaria executiva do Fórum enviar os convites, a maioria via e-mail, especialmente a partir de 2004, mas também por correio, fax e contato telefônico, foi possível observar ao longo dos anos de acompanhamento do Fórum que são as próprias organizações que participam com mais frequência as que mobilizam seus parceiros, dependendo do tema que será abordado.

Investigando os documentos disponíveis, verificou-se também que, a partir de 1999, houve uma alteração na configuração do Fórum, possivelmente em decorrência de uma mudança no contexto político-institucional, especificamente no âmbito do governo do estado do Rio Grande do Sul, com a vitória da Frente Popular, liderada pelo Partido dos Trabalhadores. Com essa mudança política, alguns programas estaduais passaram a ser debatidos com a população beneficiária. Naquele momento, segundo evidências encontradas, membros do Fórum se aproximaram de agentes do governo estadual da região. Foi nesse período, segundo Perera e Gomes (2009, p.139), que o Fórum participou da elaboração e gestão de um projeto de pesquisa apoiado com recursos públicos.

De acordo com o registro histórico realizado pelo secretário executivo à época, os primeiros nove anos de existência do Fórum geraram alguns resultados significativos:

Como resultados, destacamos a questão da socialização entre as parcerias, o nivelamento sobre a realidade da agricultura familiar, esclarecimentos e acompanhamentos de programas públicos existentes, como o Pronaf, Prodaleite, Ibama, Fepam, etc. Teve início um processo de conscientização e discussão regional sobre Agroecologia e o papel da agricultura familiar para o desenvolvimento rural desta região (Documento do Fórum de Agricultura Familiar, abril de 2004, s/p.).

No início de 2004, o Fórum passava por um momento de crise e de pouca participação das organizações, ficando entre 15 e 20 pessoas, no máximo. Baixa participação, aliás, considerando-se que, no período de 1995 a 2003 , ela era maior. Analisando atas, relatórios e listas de presença dos meses de 
junho a dezembro de 2004, verifica-se uma série de mudanças na configuração do Fórum naquele período, possivelmente em razão de uma mudança no contexto político-institucional, desta vez no âmbito do governo federal, com a vitória do Partido dos Trabalhadores (PT). Ocorre o estreitamento de laços com o governo federal, com a pesca artesanal e assentados de reforma agrária, grupos que até então não participavam do Fórum.

A partir da aproximação do governo federal em virtude de a região de abrangência do Fórum ter sido definido como um "território rural"10 , o Fórum tornou-se o espaço de gestão dessa política pública, passando a deliberar sobre o destino dos recursos do Pronaf infraestrutura e serviços, geridos pela SDT/MDA, por meio do estabelecimento formal da instituição do Fórum enquanto Comissão de Implantação das Ações Territoriais (CIAT).

Neste ponto, é preciso destacar que a aproximação de representantes da SDT/MDA junto ao Fórum também foi um processo mediado. Segundo informações coletadas, essa aproximação foi oportunizada pela participação da coordenação do CAPA, junto com representantes dos agricultores familiares e pescadores artesanais da região, em evento estadual realizado pelo MDA no primeiro semestre de 2004, no qual foi apresentada a política de desenvolvimento territorial. Associado a isso, o Fórum, pelo acúmulo de experiências e de organizações vinculadas, possuía os atributos necessários para desempenhar o papel esperado.

Cabe destacar outro fato significativo notado no período e registrado nos convites: três eventos realizados em 2004 tiveram despesas de alimentação, hospedagem e realização do evento custeados pela SDT/MDA, e foi a primeira vez na trajetória do Fórum que recursos financeiros foram disponibilizados para a implantação de projetos elaborados pelas organizações que participavam desse espaço.

Foi também no ano de 2004 que o Fórum, a partir da oferta da SDT/ MDA, escolheu uma entidade executora, o CAPA, para a formalização de contratos com essa secretaria, a fim de gerir os recursos disponíveis para custear as atividades do Fórum, assim como remunerar um profissional para atuar como articulador territorial.

Em 2005 ocorre um aumento no número de eventos, a pesca artesanal ganha espaço e os assentados de reforma agrária recuam. Nesse ano, o Fórum assumiu um novo papel junto ao governo federal, deixando de ser

\footnotetext{
${ }^{10}$ Para mais informações, vide documentos institucionais (MDA, 2005)
} 
uma comissão provisória para atuar como o Colegiado de Desenvolvimento Territorial (Codeter) ${ }^{11}$. A partir desse ano, todas as despesas de deslocamento, alimentação e, eventualmente, de hospedagem passaram a ser custeadas com recursos da SDT/MDA, por meio do contrato de repasse com o CAPA, instituição que também colocou sua capacidade instalada à disposição, incluindo a equipe técnica e sua infraestrutura, bem como sua trajetória associativa anterior.

Em 2006, os assentados de reforma agrária retomam a participação de forma ativa e amplia-se a coordenação, que desde 1995 era tripartite: um representante dos órgãos governamentais, um das organizações não governamentais e um das organizações dos agricultores familiares. A partir de 2006, mais dois representantes passaram a fazer parte da coordenação: um representante das organizações da pesca artesanal e um dos assentados de reforma agrária.

Além das mudanças na gestão, os convites e atas indicam que houve uma diversificação das pautas com presença de especialistas e discussão de temas de interesse das organizações do Fórum, independentemente dos debates para a definição dos recursos do programa, os quais também continuaram ocorrendo.

Analisando a documentação disponível, constatou-se que no ano de 2007 ocorreu uma mudança significativa no Fórum, com o ingresso de representantes de cinco $^{12}$ comunidades quilombolas, que a partir de abril passaram a participar das reuniões, e pela primeira vez participaram também do debate sobre os projetos territoriais com aprovação de demandas, o que se manteve nos anos posteriores.

\footnotetext{
${ }^{11}$ Conforme constam nos documentos oficiais, os Colegiados Territoriais são formados por representantes do governo federal e da sociedade civil. O número de integrantes depende do tamanho do território, do número de municípios e de organizações e da complexidade [presença de agricultores familiares, assentados de reforma agrária, comunidades quilombolas, pescadores artesanais, extrativistas, ribeirinhos etc.] do território representado. Os colegiados, segundo a SDT/MDA, são responsáveis por identificar as demandas locais das comunidades; promover a interação entre gestores públicos e conselhos setoriais; contribuir com sugestões para a qualificação e a integração de ações; sistematizar as contribuições para o Plano Territorial de Desenvolvimento Rural Sustentável e dar ampla divulgação às ações dos Territórios da Cidadania e dos Territórios Rurais. (SDT/MDA, 2009)

${ }^{12}$ Comunidades Quilombolas Monjolo (também conhecida por Serrinha e Campos Quevedos), Torrão e Coxilha Negra, localizadas em São Lourenço do Sul; e Armada e Maçambique localizadas em Canguçú.
} 
No ano de 2008 houve um aumento significativo no número de participantes, ampliação da coordenação e o lançamento, em fevereiro desse ano, do Programa Territórios da Cidadania ${ }^{13}$, programa de caráter interministerial coordenado pela Casa Civil da Presidência da República, inspirado pela experiência do MDA junto aos territórios rurais. O território Zona Sul do Estado/RS foi um dos selecionados para a implantação das ações previstas, e o Fórum, por ser o Colegiado Territorial, apoiou a articulação do Programa na região.

No entanto, em virtude da sua dinâmica aberta e flexível, segundo registros da época, a partir de fevereiro de 2008, ele deixa de exercer o papel de colegiado. Isso porque o Programa Territórios da Cidadania exigia que o colegiado fosse paritário, ou seja, composto por $50 \%$ de representantes da sociedade civil e $50 \%$ de representantes do poder público. Frente a esse quadro, o Fórum não se submeteu à rigidez imposta pelo programa.

De todo modo, a análise dos documentos disponíveis e a observação realizada durante o período possibilitam afirmar que o Fórum continuou sendo a grande base de sustentação, principalmente de mobilização e de articulação das organizações dos agricultores familiares, pescadores artesanais, assentados de reforma agrária e das comunidades quilombolas do território. O Fórum também manteve o papel propositivo dos projetos territoriais de investimento e de deliberação sobre os recursos da SDT/MDA, a partir desse ano como um fórum setorial do novo Colegiado Territorial.

De acordo com os dados levantados, ao final de 2008, 113 organizações participaram das atividades do Fórum. Em comparação com a lista arrolada no material de 2005, contendo 44 organizações, pode-se afirmar que houve um aumento de 2,5 vezes no número de organizações. Se considerarmos a lista com as organizações participantes em 2004 (em torno de 22), o aumento é de 5 vezes.

\footnotetext{
${ }^{13}$ Segundo Art. 2o do Decreto de 25 de fevereiro de 2008 que instituiu o Programa Territórios da Cidadania, este tem por objetivo promover e acelerar a superação da pobreza e das desigualdades sociais no meio rural, inclusive as de gênero, raça e etnia, por meio de uma estratégia de desenvolvimento territorial sustentável, que contempla: I - a integração de políticas públicas com base no planejamento territorial; II - a ampliação dos mecanismos de participação social na gestão das políticas públicas de interesse do desenvolvimento dos territórios; III - a ampliação da oferta dos programas básicos de cidadania; IV - a inclusão e integração produtiva das populações pobres e dos segmentos sociais mais vulneráveis, tais como trabalhadoras rurais, quilombolas, indígenas e populações tradicionais e; V - a valorização da diversidade social, cultural, econômica, política, institucional e ambiental das regiões e das populações.
} 
Conforme destacamos, no ano de 2008 a coordenação se amplia mais uma vez, incluindo um representante das comunidades quilombolas, e ocorre, por demanda desses representantes, o desencadeamento do processo de reconhecimento púbico das comunidades quilombolas, a partir da articulação do Fórum, evento que alterou o cenário da região. Segundo registros disponíveis, até o final do ano de 2009, 43 comunidades quilombolas foram identificadas na região sul do RS e, destas, 32 receberam as certidões emitidas pela Fundação Cultural Palmares.

No ano de 2008 também houve a descentralização das reuniões por demanda das organizações participantes, para aproximar as discussões dos públicos envolvidos, como fica evidente no deslocamento do Fórum para a Colônia de Pescadores de Pelotas.

Em 2009, o Fórum retomou as atividades junto à Embrapa, além de ser registrado um forte decréscimo no número de participantes, em média, com relação ao ano de 2008 (de 90 para 53), apesar de ser uma média semelhante à dos participantes registrados nas atividades do Fórum em 2007.

O ano de 2009 também foi marcado por uma diversidade grande de temas debatidos ao longo do ano, diminuindo significativamente as pautas relativas às ações da SDT/MDA ou de outras ações governamentais. Essa tendência se manteve em 2010, sendo marcada pela criação da campanha de preservação das sementes crioulas ${ }^{14}$ e contra o milho transgênico, resultando, em 2011, na suspensão da distribuição de sementes transgênicas num programa estadual de sementes, conhecido como Programa Troca-Troca.

Além disso, a campanha viabilizou, por meio do Fórum, a doação de sementes crioulas, de milho e feijão, para as organizações do Fórum, via Companhia Nacional de Abastecimento (Conab), e entregues em 2011, tendo sido as comunidades quilombolas as principais beneficiárias.

Em 2011, novos atores entraram em cena, provocando uma nova configuração do Fórum: representantes do governo do estado do RS, especialmente da Secretaria Estadual de Desenvolvimento Rural e da Emater, órgão oficial de extensão rural no estado e da Universidade Federal do Rio Grande do Sul (UFRGS) ${ }^{15}$. Além disso, nesse ano houve um aumento no

\footnotetext{
${ }^{14}$ Referem-se a sementes de plantas cultivadas que só foram melhoradas pelas mãos de agricultores e agricultoras, denominadas variedades tradicionais, antigas, caseiras, landraces (raças da terra) ou crioulas (PELWING et al., 2008, p.395).

${ }^{15}$ A aproximação da UFRGS se deu em virtude do edital proposto pela SDT/MDA via CNPQ para a implantação de uma célula de acompanhamento das ações territoriais.
} 
número de participantes em relação aos anos anteriores (2009 e 2010), com uma média de 75 representantes por reunião.

Em 2012, último ano da série de acompanhamento do caso estudado, verificou-se que se manteve o número de eventos realizados ao longo do ano e da média de participantes em relação ao ano anterior, mas, além das reuniões ordinárias, as organizações participantes do Fórum envolveram-se, no mês de junho desse ano, em três eventos consecutivos para propor projetos de investimento a serem apoiados por emenda parlamentar da bancada do PT na Câmara dos Deputados. Esses encontros contavam em média com 80 participantes, em boa medida pelo fato de não serem disponibilizados recursos pela SDT/MDA para apoio aos projetos territoriais como vinha ocorrendo nos outros anos, desde 2004.

Também cabe assinalar que 2012 foi o último ano de apoio financeiro às ações territoriais, mediante contrato de repasse com o CAPA, não havendo perspectivas de renovação, em virtude de novos procedimentos estabelecidos pela SDT/MDA para contratação de entidades parceiras, por meio da realização de chamadas públicas e de lotes regionais e não mais territoriais, como nos anos anteriores.

Assim como em 2011, agentes do governo estadual passaram a participar ativamente das reuniões do Fórum. Exemplo disso é a participação do diretor de produção e inovação da Agência Gaúcha de Desenvolvimento do Governo do Estado/RS na reunião de junho, o que, aliás, estimulou a elaboração e aprovação de um projeto do Fórum para o Programa Estadual de Arranjos Produtivos Locais (APL).

Segundo relatos das atividades, como o processo de eleição da coordenação ocorreu em meados de 2011 - o que nos anos anteriores era sempre realizado na primeira ou segunda reunião do ano -, ela permaneceu, em 2012, com duas substituições de pessoas - dos representantes da pesca artesanal e do MST, em decorrência da participação desses nas eleições municipais, concorrendo a cargos de vereadores ${ }^{16}$.

Pode-se observar no Gráfico 1 - o qual demonstra de forma ilustrada a variação na média de participação nas reuniões do Fórum ao longo dos anos investigados - que houve um aumento anual gradativo de participantes, tendo como ápice o ano de 2008, com a maior participação média. No entanto,

\footnotetext{
${ }^{16}$ Os dois elegeram-se pelo Partido dos Trabalhadores.
} 
mesmo com leve declínio nos anos de 2009 e 2010, o Fórum manteve a participação das organizações dos agricultores familiares, assentados de reforma agrária, e, principalmente, a permanência e o aumento no número de representantes de comunidades quilombolas.

Gráfico 1: Distribuição da média de participantes das reuniões do Fórum/ano (2004-2012)

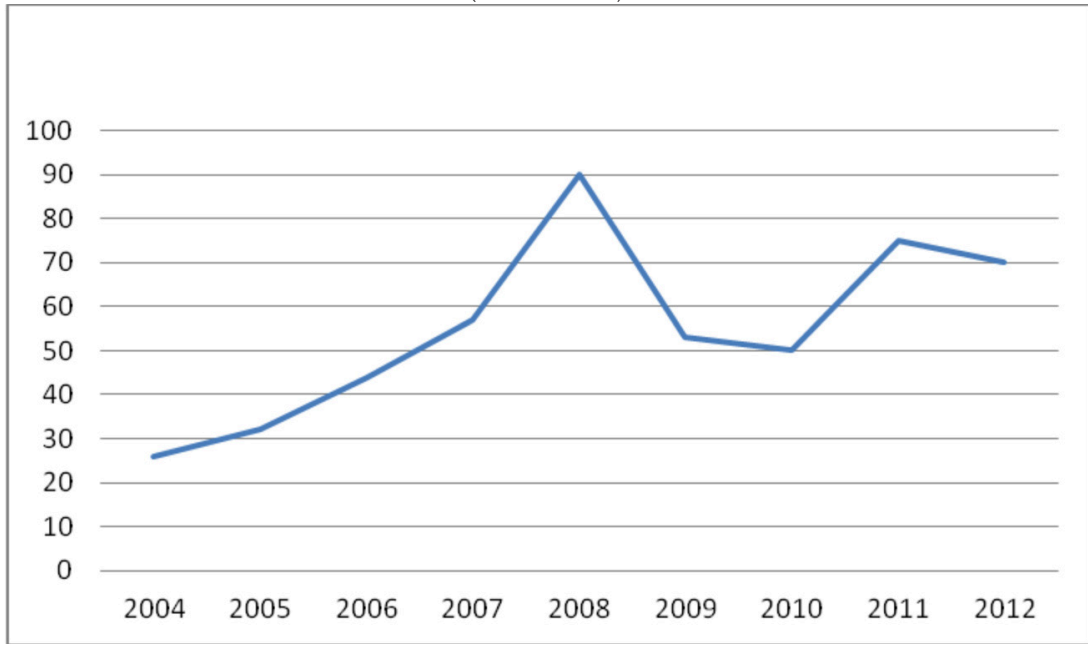

Fonte: Elaborado pela autora segundo dados das listas de presença das reuniões do Fórum

Se considerarmos os dados dos anos analisados, especialmente do início de 2004, podemos afirmar que, ao longo do período, aumentaram em sete vezes as organizações que passaram a participar das reuniões do Fórum, com frequência variável. Ao final de 2012, mais de 167 organizações diferentes haviam participado do processo. Dessas 167 organizações, 18 pertencem à pesca artesanal e 26 às comunidades quilombolas. Ou seja, foram inseridas 44 organizações que não participavam do Fórum antes de 2004 e, especialmente, as comunidades quilombolas, que nunca haviam participado de outros espaços e trouxeram consigo uma mudança no rosto do Fórum. 


\section{Considerações finais}

Como foi visto, dependendo do contexto, determinados repertórios de ação serão estimulados ou constrangidos. No caso do Fórum, percebe-se que a sua constituição esteve diretamente ligada à mudança na composição da chefia geral da Embrapa, bem como se deu num momento histórico de emergência nacional da agricultura familiar no contexto político e acadêmico.

Por sua vez, as mudanças ocorridas no contexto estadual - com o ingresso do governador ligado ao Partido dos Trabalhadores (gestão 1999-2001) e a criação de programas voltados à agricultura familiar poucos anos após a fundação do Fórum -contribuíram para a sua manutenção.

Além disso, as experiências mais institucionalizadas nas quais o Fórum inscreveu-se na região sul do RS, a partir da década de 1990, contribuíram decisivamente para sua legitimação e consequente aproveitamento das oportunidades decorrentes do contexto político-institucional. Esses casos mostram que houve uma relação entre o contexto político-institucional e as configurações do tecido associativo já existentes.

De fato foram concebidas trajetórias de experimentação social e institucional na região, envolvendo redes de organizações de agricultores familiares e organizações públicas e não governamentais. A aproximação da SDT junto ao Fórum mobilizou, aliás, as organizações da região, legitimando-o como espaço de deliberação sobre recursos públicos para investimento em projetos das organizações da agricultura familiar e não mais das prefeituras, como ocorria outrora.

Cabe destacar a importância que determinadas organizações, como a Embrapa e o CAPA, adquiriram em certos momentos da trajetória do Fórum; por exemplo, a disposição da primeira para providenciar o local de debate e implementação de políticas públicas, o que se constatou em dois momentos: 1999 e 2004. Por meio do CAPA, o Fórum obteve recursos financeiros disponibilizados pela SDT/MDA para custear suas atividades e, especialmente, dar apoio aos representantes dos agricultores familiares, pescadores(as) artesanais, assentados de reforma agrária e comunidades quilombolas. Esse apoio ocorreu, em parte, mediante o ressarcimento das despesas decorrentes da sua participação. Paralelamente, o CAPA mantinha apoio técnico às comunidades quilombolas, reforçando a importância da participação no Fórum.

Conforme já salientamos, estudos realizados por Moruzzi Marques (2009); Favareto e Demarco (apud SILVA; MARQUES, 2009); Schmitt (2012); Silva 
e Marques (2009) demonstraram que a falta de recursos financeiros é um dos principais constrangimentos ${ }^{17}$ à participação. De fato, no caso estudado, a disponibilização de recursos para esses grupos foi fundamental para o seu ingresso e permanência no processo.

Mais que isso, a SDT estabelecia em suas diretrizes a necessidade por parte dos colegiados territoriais, no caso o Fórum, de incluir representantes dos diferentes grupos que fazem parte da agricultura familiar nos processos de decisão, ou seja, estimulando pescadores artesanais e comunidades quilombolas a fazerem parte do Fórum.

No entanto, de acordo com a observação realizada durante todo o período, pode-se afirmar que a existência de espaços de participação abertos e ativos, como o Fórum, em contextos político-institucionais favoráveis a determinados repertórios e a participação efetiva dos grupos mais fragilizados, como o dos pescadores artesanais e o das comunidades quilombolas, não é um processo automático nem se limita apenas ao pagamento das despesas.

A observação realizada ao longo de todo o período em análise junto com outras informações obtidas permitem afirmar que a existência de uma organização regional, com uma trajetória institucional associativa sólida, capaz de estimular a participação de determinados grupos e garantir que as ações tenham continuidade, mesmo com a interrupção no repasse dos recursos, é fundamental para o êxito no processo.

Em relação às comunidades quilombolas, pode-se afirmar que o CAPA criou as condições de possibilidade de participação dessas junto ao Fórum, iniciando em 2000 um projeto-piloto com acompanhamento sistemático às comunidades. Cabe destacar que as primeiras comunidades quilombolas que se integraram ao Fórum em 2007 são as mesmas comunidades atendidas desde o primeiro projeto $^{18}$ desenvolvido pela instituição.

Ademais, há de se observar também os benefícios obtidos nas relações de mediação social estabelecidas entre o CAPA e as organizações da agricultura

\footnotetext{
${ }^{17}$ Em se tratando dos pescadores artesanais e dos quilombolas, podemos afirmar que os constrangimentos aumentam pelo maior grau de exclusão social, econômica e política ao qual estavam submetidos.

${ }^{18}$ Segundo Surita et al. (2007:17) O projeto Pequenos Agricultores Quilombolas considerou ações nas áreas de segurança alimentar e agroecologia; saúde comunitária e plantas medicinais; geração de renda; resgate histórico, cidadania, cultura e etnia. Ainda buscou a participação e representação social deste segmento, como instrumento decisivo de visibilidade pública, para servir como base de reconhecimento e acesso de políticas públicas.
} 
familiar, especialmente com as comunidades quilombolas. Nos últimos sete anos, a organização ganhou dois prêmios nacionais, dois prêmios internacionais e um prêmio estadual em reconhecimento ao trabalho realizado na região.

O processo de mediação social, longe, então, de ocorrer de forma espontânea e imediata, se deu em um contexto determinado, em dado período e sob certas circunstâncias. O próprio ambiente de trocas e interdependências analisado também sofreu a influência do contexto político-institucional, que atuou estimulando e potencializando determinados tipos de mediação social e diferentes repertórios de ação coletiva, detectada particularmente na reprodução do Fórum a partir da aproximação da SDT/MDA.

Pode-se afirmar que a mobilização de recursos foi um fator estratégico para a manutenção e ampliação do Fórum, o que vem a coincidir, também, com a perspectiva de Isunza Vera (2007), no sentido de que, no processo de participação social, os cidadãos mobilizam energias e recursos em um fluxo contínuo de intercâmbios com as instituições do Estado, materializando-se em atores concretos, como o do Fórum.

Além disso, os resultados encontrados extrapolaram as hipóteses iniciais, as quais foram comprovadas, e outros quatro elementos surgiram do trabalho de campo e foram identificados como responsáveis pela manutenção do Fórum: a capacidade deste de gerar resultados, de manter uma agenda mais ampla e diversificada do que a mera gestão dos recursos de um programa, a capacidade de renovar as parcerias, concomitantemente às mudanças no contexto político-institucional, e de se adaptar à entrada de novos grupos, como os assentados de reforma agrária e pescadores artesanais em 2004 e das comunidades quilombolas em 2007, incluindo-os, inclusive, na coordenação.

Ademais, houve ao longo do período analisado um fortalecimento dos laços entre sociedade civil e Estado. As organizações do Fórum não só deliberaram como também participaram da implementação das suas decisões. O caráter deliberativo assumido pelo Fórum na sua relação com a SDT/MDA é uma dimensão importante para sua vitalidade, além do fato de as organizações não se restringirem ao ato de referendar as propostas das equipes técnicas e dos dirigentes políticos municipais, estaduais ou federais.

Adicionalmente, o fato de o Fórum apresentar com clareza os procedimentos de deliberação e o volume de recursos em discussão somado ao esforço para executar as ações contidas no PTDRS contribuíram significativamente para sua legitimação enquanto espaço institucional 
privilegiado para que a população encaminhasse suas demandas.

A eficácia da participação e o grau de comprometimento do governo federal, especificamente da SDT/MDA no atendimento às prioridades definidas pelo Fórum, enquanto colegiado territorial, coloca-se como mais uma variável de manutenção e reprodução, visto que no período investigado foram destinados recursos do governo federal para projetos deliberados pelo Fórum.

Esse Fórum pode ser considerado um caso bem-sucedido de participação social, com uma duração que, em 2014, completa 19 anos de existência. Entre reconfigurações e mediações, o Fórum foi construindo sua trajetória, renovando-se anualmente, integrando novas pautas e, principalmente, novos atores sociais. Por sua flexibilidade e capacidade de se adaptar aos diferentes contextos político-institucionais, soube aproveitar as oportunidades políticas apresentadas, conquistando legitimidade e resultados para a agricultura familiar regional.

Ademais, considerando que o Fórum está inserido numa dinâmica nacional de articulação com o Estado e que suas configurações permitem reflexões ampliadas sobre as relações desencadeadas, utilizá-lo como referência torna-se relevante para novas pesquisas científico-sociais sobre esse tema na realidade brasileira, sendo necessário um aprofundamento teórico que permita analisar a série de temas apresentados a partir do universo empírico demonstrado.

\section{Referências}

ANGROSIN0, Michael.

(2009). Observação Etnográfica. In: Etnografia e observação participante. Porto Alegre: Artmed.

ARRETCHE, Martha.

(2003). Financiamento federal e gestão local de políticas sociais: o difícil equilíbrio entre regulação, responsabilidade e autonomia. Ciência e Saúde Coletiva, vol.8 (2), p.331-345.

BECKER, Howard.

(1999). Problemas de inferência e prova na observação participante. Métodos de Pesquisa em Ciências Sociais. São Paulo: Hucitec.
CENTRO DE APOIO AO PEQUENO AGRICULTOR (CAPA).

(2009). PTDRS - Plano Territorial de Desenvolvimento Rural Sustentável: território da cidadania Zona Sul do Estado do Rio Grande do Sul. Pelotas.

(2008). Território Zona Sul do Estado Rio Grande do Sul. Pelotas.

CELLARD, André.

(2010). A análise documental. In: Jean Poupart et al. ; A pesquisa qualitativa: enfoques epistemológicos e metodológicos. Trad. Ana Cristina Nasser. 2. ed. Petrópolis, RJ: Vozes. 
DE LA GARZA.

(2001). La epistemología crítica y el concepto de configuración. Revista Mexicana de Sociología. Disponivel em: http://docencia. izt.uam.mx/egt/publicaciones/articulos/ configuraciones.pdf. Acesso em 14 novembro de 2012.

ELIAS, Norbert.

(2008). Introdução à sociologia. Portugal, Lisboa: EDIÇÕES 70 Ltda.

(2006). Escritos \& ensaios: Estado, processo, opinião pública. Rio de Janeiro: Jorge Zahar Ed. (2001). A sociedade de corte: investigação sobre a sociologia da realeza e da aristocracia de corte. Rio de Janeiro: Jorge Zahar.

(1998). Envolvimento e alienação. Rio de Janeiro: Bertrand Brasil.

FAVARETO, Arilson; DEMARCO, Daniel.

(2009). Entre o capital social e o bloqueio institucional: uma avaliação dos CMDR em cinco Estados brasileiros. In: Sérgio Schneider; Marcelo Kunrath Silva; Paulo Eduardo Moruzzi Marques (Orgs); Políticas públicas e participação social no Brasil Rural. 2. ed. Porto Alegre: Editora da UFRGS.

\section{FÓRUM DE AGRICULTURA FAMILIAR.}

(2004-2012). Atas, documentos, relatórios, listas de presença, Arquivo CAPA, Pelotas/RS.

GIL, Antônio Carlos.

(2009). Observação. Métodos e técnicas de Pesquisa Social. São Paulo: Atlas.

IDE, Hans-Ullrich.

(2008). A gente pega junto: protagonismo na agricultura familiar. Porto Alegre: [s.n.]

ISUNZA VERA, Ernesto.

(2007). Instituciones y actores de la participación ciudadana en México. ¿Salida coyuntural a la crisis de legitimidad o cambios estructurales para la democratización? In: Evelina Dagnino; Luciana Tatagiba (Orgs.); Democracia, sociedade civil e participação. Chapecó: Argos.
MARTINS, José de Souza.

(2008). A aparição do demônio na fábrica (Origens sociais do Eu dividido no subúrbio operário). São Paulo: Editora 34.

MATTEI, Lauro; CAZELLA, Ademir.

(2009). Planejamento e gestão do Pronaf Infra-estrutura e Serviços: evidências a partir do Estado de Santa Catarina. In: Sérgio Schneider; Marcelo Kunrath Silva; Paulo Eduardo Moruzzi Marques (Orgs); Políticas públicas e participação social no Brasil Rural. 2. ed. Porto Alegre: Editora da UFRGS.

McADAM, Doug; TARROW, Sidney; TILLY, Charles.

(2001). Dynamics of contention. Cambridge: Cambridge University Press.

MINISTÉRIO DO DESENVOLVIMENTO AGRÁRIO.

(2005a). Referências para uma Estratégia de Desenvolvimento Rural Sustentável no Brasil. Brasília: MDA/SDT - CONDRAF.

(2005b). Marco Referencial para Apoio ao Desenvolvimento de Territórios Rurais Documento Institucional 02. Brasília: MDA/ SDT.

MORUZZI MARQUES, Paulo Eduardo.

(2009). Participação e Pronaf: um estudo do poder, dos atores e dos conflitos em torno dos conselhos municipais e de desenvolvimento rural. In: Sérgio Schneider; Marcelo Kunrath Silva; Paulo Eduardo Moruzzi Marques (Orgs); Políticas públicas e participação social no Brasil Rural. 2. ed. Porto Alegre: Editora da UFRGS.

NEVES, Delma Pessanha.

(2008). Mediação social e mediadores políticos. In: NEVES, Delma Pessanha (0rg.); Desenvolvimento Social e mediadores políticos. Porto Alegre: Editora da UFRGS.

NUSSBAUMER, Beatriz; ROS, Carlos Cowan. (2011). Trayectoria conceptual de la mediación social: expedicionarios, patrones, políticos y profesionales técnicos en la interconexión y producción de mundos de significados. In: Beatriz Nussbaumer; Carlos Cowan Ros (ed.); Mediadores sociales: en la producción 
de prácticas e sentidos de la política pública. Buenos Aires: Fundación CICCUS.

PELWING, Andréia Becker; FRANK, Lúcia Brandão; BARROS, Ingrid Bergman de

(2008). Sementes crioulas: o estado da arte no Rio Grande do Sul. RER, Piracicaba, SP, vol. 46, no 02, p. 391-420. Disponível em http:// www.scielo.br/pdf/resr/v46n2/v46n2a05. pdf. Acesso em 27 março de 2013.

PERERA, Apes Falcão; GOMES, João Carlos Costa.

(2009). 0 uso de metodologias participativas na democratização do conhecimento: avaliação de rede de referência na Região Sul do RS. Revista Extensão Rural, Ano XVI, n 18, p.123 $-146$.

REICHERT, Lírio José, GOMES, João Carlos Costa (2006). Pesquisa participativa em rede de referência. Revista Brasileira de Agroecologia, Vol. 1, no 1.

RUBERT, Rosane. Aparecida, SILVA, Paulo Sérgio

(2009). 0 acamponesamento como sinônimo de aquilombamento: o amálgama entre resistência racial e resistência camponesa em comunidades negras rurais do Rio Grande do Sul. In: Diversidade do campesinato: expressões e categorias: construções identitárias e sociabilidades. v.1. São Paulo: Editora UNESP; Brasília, DF: NEAD.

SCHMITT, Claudia Job (Coord.).

(2012). Relatório de Pesquisa: Políticas em rede: uma análise comparativa das interdependências entre o Programa de Aquisição de Alimentos e as redes associativas na Bahia e no Rio Grande do Sul. Rio de Janeiro: UFRRJ.

SCHNEIDER, Sérgio; CAZELLA, Antônio Ademir; MATTEI, Lauro.

(2009). Histórico, caracterização e dinâmica recente do Pronaf - Programa Nacional da Agricultura Familiar. In: Sérgio Schneider; Marcelo Kunrath Silva; Paulo Eduardo Moruzzi Marques (Orgs); Políticas públicas e participação social no Brasil Rural. 2. ed. Porto Alegre: Editora da UFRGS.
SILVA, Marcelo Kunrath.

(2007). Dos objetos às relações: esboço de uma proposta teórico-metodológica para análise dos processos de participação social no Brasil. In: Evelina Dagnino; Luciana Tatagiba (Orgs); Democracia, sociedade civil e participação. Chapecó: Argos.

SILVA, Marcelo Kunrath; SCHNEIDER, Sérgio.

(2009). A participação dos agricultores nas políticas de desenvolvimento rural: uma análise do Pronaf Infra-estrutura e Serviços no Estado do Rio Grande do Sul (1997 2000). In: Sérgio Schneider; Marcelo Kunrath Silva; Paulo Eduardo Moruzzi Marques (Orgs); Políticas públicas e participação social no Brasil Rural. 2. ed. Porto Alegre: Editora da UFRGS.

SILVA, Marcelo Kunrath; MORUZZI MARQUES, Paulo Eduardo.

(2009). Democratização e políticas públicas de desenvolvimento rural. In: Sérgio Schneider; Marcelo Kunrath Silva; Paulo Eduardo Moruzzi Marques (Orgs); Políticas públicas e participação social no Brasil Rural. 2. ed. Porto Alegre: Editora da UFRGS.

SKOCPOL, Theda.

(2003). Diminished Democracy: from membership to management in American civic life. Norman: University of Oklahoma Press.

SURITA, Rita et al.

(2007). Descobri que tem raça negra aqui. Pelotas: s. ed.

ZARTH, Paulo Afonso

(2002). Do arcaico ao moderno: o Rio Grande do Sul agrário do século XIX. Ijuí: Ed. Unijuí.

\section{Recebido em}

janeiro de 2014

\section{Aprovado em}

março de 2015 